\title{
Internal and forced variability along a section between Greenland and Portugal in the CLIPPER Atlantic model
}

\author{
Anne Marie Treguier ${ }^{1,{ }^{*}}$, Claire Gourcuff ${ }^{1}$, Pascale Lherminier $^{1}$, Herle Mercier $^{1}$, \\ Bernard Barnier ${ }^{2}$, Gurvan Madec ${ }^{3}$, Jean-Marc Molines ${ }^{2}$, Thierry Penduff ${ }^{2}$, Lars Czeschel ${ }^{4}$ and \\ Claus Böning ${ }^{4}$
}

(1) Laboratoire de Physique des oceans, CNRS-Ifremer-UBO, Brest, France

(2) Laboratoire des Ecoulements Geophysiques et Industriels, Joseph Fourier University, Grenoble, France

(3) LOCEAN, Laboratoire d'oceanographie et du climat, Universite de Paris VI, Paris, France

(4) IFM-GEOMAR, Kiel, Germany

\section{*: Corresponding author : Anne.Marie.Treguier@ifremer.fr}

\begin{abstract}
:
Numerical models are used to estimate the meridional overturning and transports along the paths of two hydrographic cruises, carried out in 1997 and 2002 from Greenland to Portugal. We have examined the influence of the different paths of the two cruises and found that it could explain 0.4 to $2 \mathrm{~Sv}$ of difference in overturning (the precise value is model-dependent). Models show a decrease in the overturning circulation between 1997 and 2002, with different amplitudes. The CLIPPER ATL6 model reproduces well the observed weakening of the overturning in density coordinates between the cruises; in the model, the change is due to the combination of interannual and high-frequency forcing and internal variability associated with eddies and meanders. Examination of the $z$-coordinate overturning reveals model-data discrepancies: the vertical structure in the models does not change as much as the observed one. The East Greenland current variability is mainly wind-forced in the ATL6 model, while fluctuations due to eddies and instabilities explain a large part of the North Atlantic Current variability. The time-residual transport of dense water and heat due to eddy correlations between currents and properties is small across this section, which is normal to the direction of the main current.
\end{abstract}

Keywords: Oceanography - Climate variability - North Atlantic-Thermohaline circulation - Ocean model 


\section{Introduction}

The thermohaline circulation of the North Atlantic ocean brings warm water to the Nordic Seas and exports cold North Atlantic deep water to the world ocean. Considering its importance for the regional climate, great efforts are put into observing and monitoring this circulation. It is a difficult task because it requires observations over the whole water column on a transatlantic section, which only ship-borne observations can provide. Due to the high cost of hydrographic cruises, sections are not sampled often. Attempts at continuous monitoring are being made in the North Atlantic subtropical gyre (RAPID project, Hirschi et al. 2003). In the subpolar gyre, our knowledge of the thermohaline circulation still relies on rather sparse hydrographic sections. In 2002, a series of measurements between Greenland and Portugal has been initiated by the OVIDE project, in the framework of CLIVAR. The cruise will be repeated every two years during a decade. The path of the OVIDE section is quite similar to the "4X" cruise sampled in 1997 (Alvarez et al., 2002), as indicated in Fig. 1. Both cruises have been carried out in summer. Lherminier et al. (2006) have thus discussed the variability of the thermohaline circulation (THC) by comparing the 1997 and the 2002 measurements. The THCs estimated for the two cruises are quite different, lower for OVIDE. Lherminier $e t$ al. (2006) show that the decrease is due in part to a reduction of the vertical overturning circulation driven by the deep overflow transports and in part to a change in the horizontal circulation (a weakening of the East Greenland current) that both contributes to the southward limb of the THC. Of course, the interpretation of those two snapshots, five years apart, is very difficult. Do the observations demonstrate 
a long-term decline in the THC? Or rather, are the differences due to short-term fluctuations of the currents, or mesoscale eddies? Can the slightly different section paths explain part of the decrease between 1997 and 2002?

In theory, high resolution numerical models should answer all those questions. Unfortunately, today's models do not perform very well in the North Atlantic subpolar gyre. Treguier et al. (2005) have compared four state-of-the-art high resolution ocean models and documented problems with represention of the deep overflows from the Nordic Seas, salinization of the Labrador sea, and excessive convection in the Labrador and Irminger Sea. On the other hand, many aspects of the circulation were similar across models. For example, the four high resolution models showed a continuous boundary current all around the northern subpolar gyre, with strong Greenland and Labrador currents (35 to $60 \mathrm{~Sv}$ of transport). Previous modelling studies have also shown that the models' interannual variability driven by atmospheric fluxes tends to be robust. Beismann et al.(2002) considered three different models and found similar time series of anomalies of the Atlantic meridional overturning at $45^{\circ} \mathrm{N}$.

These results motivate the present analysis of the variability between the $4 \mathrm{X}$ (1997) and OVIDE (2002) cruises in numerical models. Although the models cannot provide definitive answers, they help understand some of the mechanisms generating variability and quantify their respective importance. Our main tool is ATL6, a $1 / 6^{\circ}$ Atlantic model developped within the CLIPPER project. It has been used recently by Penduff et al. (2004) to investigate the interannual variability of eddy kinetic energy (EKE) in the North Atlantic. The model reproduced the shift in EKE 
observed by satellite altimetry in 1995. Penduff et al. (2004) showed that it was the result of a change of the ocean circulation forced by a slow, NAO-related, shift of the storm track, rather than a local response of EKE to high frequency wind forcing. Lumpkin et al. (2005) have studied the variability of transports across a hydrographic section at $48^{\circ} \mathrm{N}$ (5 repeats), using an inverse box model. They find a small variability of the meridional overturning (a few sverdrups) which is in very good agreement with the ATL6 model results (their Fig. 12). One interesting feature of ATL6 is the availability of twin experiments, one forced by a repeated seasonal cycle and the other by daily atmospheric forcings varying from year to year. The comparison of the two experiments allowed Hall et al. (2004) to estimate the contribution of the model internal variability (eddies and meanders) to the interannual variations of heat transport. These two experiments will allow us to distinguish between internal and forced variability across the OVIDE section. We also consider results of a recent experiment carried out with the FLAME model (a Family of Linked Atlantic Models, Eden and Böning, 2002), with twice the horizontal resolution of ATL6 $\left(1 / 12^{\circ}\right)$. FLAME results represent a huge database and the CLIPPER analysis tools cannot be used due to the model's different grids. For this reason, only a few FLAME time-averages are used in our paper, to complement ATL6 results.

Both ATL6 and FLAME have certain limitations. The most stringent is probably the northern limit of the models $\left(70^{\circ} \mathrm{N}\right)$. Boundary conditions at the northern boundary (FLAME) or in the northern buffer zone (ATL6) are derived from seasonal climatologies. The models do not allow interannual variability to develop 
in the Nordic Seas that could in turn affect the overflows and the OVIDE section downstream. Our investigation of the variability is thus restricted to mechanisms acting in the subpolar North Atlantic itself, independently of the Nordic Seas or the Arctic. Despite this limitation, we will see that some features of ATL6 solutions compare well with the global model of Marsh et al. (2005). We also note that one of the most exhaustive studies of forced ocean variability in the subpolar gyre was performed by Eden and Jung (2001) and Eden and Willebrand (2001), using the FLAME Atlantic model domain closed at $70^{\circ} \mathrm{N}$. We thus feel that an analysis of the variability in those models is justified at the present stage and may help interpret the data, provided that the model deficiencies are properly documented and taken into account.

Our study concentrates on two aspects of the variability. After a presentation of the model, we discuss zonally integrated quantities: the $z$-coordinate meridional overturning streamfunction in section 3 , and the density coordinates circulation in section 4 . We then proceed to examine the variability of current systems, first the poorly sampled East Greenland current and then the North Atlantic current as well as its recirculations.

\section{The numerical experiments}

The CLIPPER project was initiated in 1995 by Christian Le Provost, bringing together for the first time modelling teams in laboratories in Grenoble, Brest, Paris and Toulouse. The aim was to provide a modelling background to help the analysis of the French WOCE hydrographic cruises in the South Atlantic. A regional model 
has been built, covering the Atlantic ocean from Drake passage to $30^{\circ} \mathrm{E}$ and from Antarctica $\left(75^{\circ} \mathrm{S}\right)$ to $70^{\circ} \mathrm{N}$. The model used in the present work was set up in 1999: it has a resolution of $1 / 6^{\circ}$ at the equator, and is referred to as ATL6. At the time it represented the best trade-off in terms of model domain and model resolution.

Like the German FLAME effort, CLIPPER builds on the European DYNAMO intercomparison project (Willebrand et al. 2001). CLIPPER also relies on a previous modelling effort in the South Atlantic (de Miranda et al. 1999) carried out at LEGI (Laboratoire des Ecoulements Geophysiques et Industriels, Grenoble) while Christian Le Provost was the head of the ocean modelling team there. The experience gained during those projects helped define the boundaries of the ATL6 domain. ATL6 has four open boundaries at Drake passage $\left(68^{\circ} \mathrm{W}\right)$, at $30^{\circ} \mathrm{E}$ between Africa and Antarctica, at $8^{\circ} \mathrm{W}$ in the Gulf of Cadiz and at $70^{\circ} \mathrm{N}$ beyond the sills of the Nordic seas. Data at the open boundaries are taken from hydrography and are fixed in time. Buffer zones are defined in the Norwegian Sea, Baffin Bay, and Weddell sea, where the model temperature and salinity are relaxed to seasonal climatology.

ATL6 is based on the primitive equation code OPA8.1 developed at LODYC (Madec et al., 1998), a second order finite difference model with a rigid lid. The vertical grid has 42 geopotential levels with a grid spacing of $12 \mathrm{~m}$ at the surface and $200 \mathrm{~m}$ below $1500 \mathrm{~m}$. The bathymetry is calculated from Smith and Sandwell (1997), and the model is initialized using the seasonal climatology of Reynaud et al. (1998). A horizontal biharmonic operator is used for lateral mixing of tracers and momentum, with a coefficient varying as the third power of the grid spacing 
following Willebrand et al. (2001). The vertical mixing of momentum and tracers is calculated using a second-order closure model (Madec et al., 1998). In case of static instability the vertical mixing coefficients are set to a very large value $\left(1 \mathrm{~m}^{2} \cdot \mathrm{s}^{-1}\right)$.

Three ATL6 experiments with different forcing fields and duration are considered in this paper (Fig. 2). All use data from ECMWF (European Center for Medium range Weather Forecast). The heat flux is formulated as suggested in Barnier et al. (1995), using their feedback coefficient for relaxation to the Reynolds SST field. The evaporation minus precipitation (E-P) fluxes are formulated as a pseudo salt flux, including river run-off (Treguier et al., 2001), as well as a relaxation to observed sea surface salinity (Levitus et al., 1998) with the same coefficient as for temperature. The first experiment, ATL6-clim, is forced by the climatology of the ECMWF reanalysis ERA-15. Fluxes are averaged over the period 1979 to 1993 , and the wind stress is smoothed using a 10-days filter to remove all synoptic variability. This experiment is 28 years long. The second experiment, ATL6-00, starts after 8 years of ATL6-clim with an interannual integration using daily winds and fluxes of ERA15 (1979 to 1993). For years 1994 to 1999 , the experiment has been pursued using wind stress of the ECMWF analysis, and anomalies of ECMWF analysis fluxes combined with the mean values of the reanalysis. ATL6-00 was meant to be a long interannual experiment with an atmospheric forcing as consistent as possible over the whole period (this consistency has been verified by Penduff et al., 2004). The procedure of combining the analysis and reanalysis however made it difficult to continue the experiment for more 
recent years. A third, shorter experiment was thus started without spin-up, using daily ERA15 forcing for years 1990 to 1993 and the ECMWF analysis for years 1994 to 2002. This latter experiment (ATL6-02) covers the period of the 1997 and 2002 cruises considered in this paper. As mentioned in the introduction, the ATL6-clim experiment with repeated seasonal cycle forcing is extremely useful to separate the variability due to intrinsic model instabilities from the effects of high frequency and interannual forcing (see for example Penduff et al., 2004 or Hall et al., 2004).

The circulation and water mass properties of the ATL6 model have been evaluated in the subpolar gyre by Treguier et al. (2005, hereafter T05), and compared with other high resolution models. All ATL6 run share similar characteristics: a rather strong barotropic circulation (40-45 Sv south of Cape Farewell, Fig. 1), and an excessive salinization of the Irminger and Labrador Sea. The salinity problem is found in most high resolution models of the subpolar gyre and is discussed in detail by T05; multiple possible causes exist that will not be recalled here. Time series of barotropic transport, mixed layer depth and density in the Labrador and Irminger Sea in ATL6-00 (T05, figure 7), show interannual variability similar to the low resolution model of Eden and Willebrand (2001). This led T05 to conclude that the ocean variability forced by atmospheric wind and fluxes is robust across different models, at least to some extent (this was also demonstrated by Beismann et al., 2002). Based on this previous model intercomparison, we will try to emphasize the aspects of the variability which we believe are well represented in ATL6. 
The FLAME $1 / 12^{\circ}$ model is based on a refined configuration of the Modular Ocean Model (Pacanowski, 1995), a primitive equation model on a B grid. The model has 45 levels in the vertical, with spacing of $10 \mathrm{~m}$ at the top and $250 \mathrm{~m}$ at the bottom. A few differences with the configuration described by Eden and Böning (2002) are documented by Czeschel (2004). An advective and diffusive bottom boundary layer scheme is used, as well as an isopycnal mixing of tracers. The Northen boundary at $70^{\circ} \mathrm{N}$ is open and a time-invariant condition is prescribed based on an Arctic model (R. Gerdes and J. Brauch, personal communication). The model is spun-up for 10 years using the ECMWF-based climatological forcing fields of the DYNAMO experiment (Willebrand et al. 2001). An interannual experiment is then run for years 1987 to 2004 . The forcing is calculated by adding monthly net heat flux and wind stress anomalies (extracted from the NCEP-NCAR reanalysis data) to the DYNAMO climatological forcing, following the formulation of Eden and Willebrand (2001). Since their experiments showed the freshwater flux anomalies (originating from evaporation and precipitation variability in the model domain) to be of minor importance for the oceanic response, such anomalies were not considered in the present experiment, i.e., sea surface salinity was restored to monthly climatological values. Three time-averaged fields are used in the present paper: the 1995-2002 mean and monthly averages at the time of the $4 \mathrm{X}$ and OVIDE cruises. 


\section{Variability of the $z$-coordinates overturning between 1997 and 2002}

To characterize the thermohaline circulation, observational and modelling studies consider either the $z$ coordinates overturning, or the overturning in density or neutral coordinates. In the North Atlantic the overturnings in $z$ coordinates and isopycnal coordinates usually vary in the same fashion: the decrease found between sections 4X and OVIDE applies to both (Lherminier et al. (2006, hereafter LH06). We will start here by considering the meridional overturning streamfunction calculated in $z$ coordinates (MOC hereafter). Note that the MOC is a linear function; it can be calculated directly from model time-mean fields and has no eddy contribution.

We define the MOC intensity as the maximum of the southward transport integrated from the bottom (the maximum is reached typically near $1000 \mathrm{~m}$ depth in the model). Fig. 3a shows its time series along the OVIDE cruise path in the ATL6-02 experiment. Using inversions based on hydrography and ADCP measurements, LH06 find $12.6 \pm 1 \mathrm{~Sv}$ for the $4 \mathrm{X}$ cruise in the summer of 1997 , and $8.5 \pm 1 \mathrm{~Sv}$ for OVIDE in the summer of 2002 (circles in Fig. 3a). Note that the $4 \mathrm{X}$ value is lower than the one previously published by Alvarez et al. (2002): this is discussed in detail by LH06. The model MOC does not decrease as much as observed between 1997 and 2002 (Fig. 3a). A high frequency variability stands out, with peak-to-peak amplitude of about $8 \mathrm{~Sv}$. The high frequency variability of the MOC in models is usually correlated with the variability of the net Ekman transport (Eden and Willebrand, 2001). It is certainly the case for the OVIDE section in ATL6, as shown in Fig. 3c. When the Ekman transport is removed from the MOC, 
the range of high frequency variability is reduced (thin black line on Fig.3b). To investigate the sources of the remaining variability, we also show in Fig. $3 b$ the time series for ATL6-clim (forced by a repeated seasonal cycle). The range of MOC variations in ATL6-clim is much smaller than in ATL6-02 (3 Sv rather than $8 \mathrm{~Sv})$. The absence of a clear seasonal cycle is quite striking; the MOC variability in ATL6-clim is dominated by the effect of instabilities and eddies. Even with Ekman contribution removed, ATL6-02 still has a larger variability than ATL6-clim (the standard deviations for those two curves in Fig $3 \mathrm{~b}$ are $1.2 \mathrm{~Sv}$ and $0.7 \mathrm{~Sv}$ respectively). This suggests another source of variability besides eddies and direct response to Ekman. Many mechanisms can provide high frequency response to the forcings, for example barotropic and topographic Rossby waves. Our model results suggest that such processes could contribute a few sverdrups of MOC variability along the OVIDE section on a monthly time scale.

A detailed model-data comparison must take into account both the different time period of the two cruises and the different cruise path: such estimates are given in Table 1 for ATL6 and in Table 2 for FLAME. In ATL6, the MOC averaged over years 1995 to 2002 is $12.1 \mathrm{~Sv}$ along the OVIDE path and 13.6 Sv along the $4 \mathrm{X}$ path, a difference of $1.5 \mathrm{~Sv}$ in the mean (Table 1). In the FLAME model, the difference between the two paths is smaller (0.6 Sv, Table 2) while in the ATL6clim climatological experiment it is larger $(2.2 \mathrm{~Sv})$. Note that the time-averaged Ekman transport is similar on both sections for ATL6: $1.1 \mathrm{~Sv}$ southwards along the OVIDE path and 1.3 Sv along the 4X path (for the average of years 19952002), while it is quite different for FLAME which has a positive (northward) 
Ekman transport along the $4 \mathrm{x}$ path, due to a different wind stress forcing. The fact that the MOC is larger along $4 \mathrm{X}$ for all the models suggests that the difference in cruises path may contribute part of the 4 Sv MOC difference between the data of OVIDE and 4X. However, the magnitude of this effect varies between models and experiments; moreover it varies on monthly and interannual time scales as does the MOC itself. The models conserve mass exactly, so the difference in MOC integrated from the bottom at the two sections is the sum of two terms. The first term is the vertical velocity at the level of the maximum overturning (around $1000 \mathrm{~m}$ in the models) integrated over the area between the section paths. The second term is the meridional transport due to the difference in depth of the maximum overturning (it is one model level deeper along $4 \mathrm{X}$ compared with OVIDE). Considering the large influence of resolution and topography on vertical velocities in primitive equation models, it is not surprising that the MOC difference between the two cruise paths is not robust across models.

Let us come back to Tables 1 and 2 and consider now the interannual differences. The monthly mean MOC in ATL6 is $13.4 \mathrm{~Sv}$ for the time and path of the $4 \mathrm{X}$ cruise and 10.6 Sv for OVIDE. This drop of 2.8 Sv between August 1997 and June 2002 is comparable to, although smaller than, the observed difference of $4 \mathrm{~Sv}$. In the ATL6 model, this drop is explained in part by the different path of the sections and by interannual variability of the Ekman transport. The remaining difference is caused by the model response (other than Ekman) to the interannual wind and fluxes, and by the model internal variability (eddies). Dedicated sensitivity studies would be needed to separate those two factors precisely; note that because the 
model is not constrained by observations, its eddy fluctuations are not in phase with the real ocean. Examination of the ATL6-clim experiment provides an order of magnitude of eddy effects: eddies alone can cause up to $1.5 \mathrm{~Sv}$ difference between two summer sections taken in different years.

The monthly mean MOC in FLAME is $8.9 \mathrm{~Sv}$ for the time and path of the 4X cruise and 7.9 Sv for OVIDE. Values along the two paths are always closer in FLAME as discussed previously. The different behavior of FLAME may be due to the different forcing (the ATL6 forcing is very close to the ERA40 wind data that have been used in the inversion of LH06, while the FLAME forcing is not). Different topography and vertical velocity patterns may also play a part. A full analysis of the variability in the FLAME $1 / 12^{\circ}$ model is beyond the scope of this paper, but the few snapshots presented here indicate a relatively stable MOC between 1997 and 2002 in agreement with the time series of ATL6 displayed in Fig 3.

The evolution of the MOC in ATL6 can be compared to the results of the global $1 / 4^{\circ}$ OCCAM model (Marsh et al. 2005). Note that our MOC differs slightly from theirs: using their definition would increase our numbers by $1 \mathrm{~Sv}$ (corresponding to the northward transport of bottom water). In both ATL6 (Fig. 3a) and OCCAM (Marsh et al. 2005, their Fig. 4a), there are maxima in 1995 and 1997 followed by a decline of the MOC over the next years. Considering annual means, the decrease is $1.5 \mathrm{~Sv}$ between 1995 and 2002 in ATL6, while it is larger in the OCCAM model: a decline of about $3 \mathrm{~Sv}$ occurs between 1991 and 2002. There is no such long-term decrease in ATL6-02, nor in the long experiment ATL6-00, where the overturning 
remains stable between 1980 and 1999 (not shown). However, the shorter term drop of 1.5 Sv between 1997 and 1999 appears in ATL6-02, ATL6-00 and OCCAM, suggesting that this feature is a model response to the forcings rather than a model drift. Regarding the long term tendencies, the quantitative difference of behavior between ATL6 and OCCAM may be due to the fact the latter is a global model; it may thus be able to reproduce variability on the OVIDE section driven by changes in the nordic seas which ATL6 does not represent. However, OCCAM has a strong drift in the deep water masses north of the sills. Marsh et al. (2005) mention a decrease in dense water volume at a rate of $1 \mathrm{~Sv}$ between 1985 and 2002 , so that more model analysis is required to assess the realism of the decline of the MOC found in OCCAM.

An important result of LH06 is the large difference in the vertical structure of the MOC between the 19974 X cruise and OVIDE 2002. Transport profiles are reproduced in Fig. 4 with ATL6 model results, and in Fig. 5 with the FLAME model. Note that they are not integrated over depth, in order to emphasize differences in structure (the MOC is the integral of those curves). The observed transport for the OVIDE cruise shows two maxima of southward flow, one around $2600 \mathrm{~m}$ and the other around $1600 \mathrm{~m}$. The deeper maximum, related to the overflows, is absent in ATL6. This is probably due to excessive mixing downstream of the sills in the model, resulting in a North Atlantic Deep Water that is too shallow. The observed intensification of the transport is deeper and more intense in the $4 \mathrm{X}$ inversion (Fig. 4b). This constrasts with the model's MOC structures, which are similar at OVIDE and 4X. The vertical structure of the transport in FLAME (Fig. 5) has 
two well-defined maxima of about the same strength at $3000 \mathrm{~m}$ and $1500 \mathrm{~m}$ : its MOC structure is thus intermediate in shape between the $4 \mathrm{X}$ and OVIDE inversions. The presence of the deep maximum is due to the better representation of the dense overflows in FLAME. However, this vertical structure does not vary significantly for the three time periods considered in our study, just as was the case for ATL6. The vertical structure in the models does not vary much between the two section paths either. This model-data discrepancy may have various origins. The different structure between the $4 \mathrm{X}$ and OVIDE data inversion is mainly due to a larger outflow of deep water in the Irminger Sea (a larger transport of overflow water and less recirculation in $4 \mathrm{X}$ ) as well as a deeper Iceland-Scotland overflow water in $4 \mathrm{X}$ due to mixing and deepening of the flow at the Charlie-Gibbs fracture zone (see LH06 for details). Maybe the models lack variability in the overflows, due to their use of climatological conditions at the northern boundaries; maybe their spatial resolution is not good enough to represent local variability near the Charlie-Gibbs fracture zone; but it may also be the case that the inversions overestimate the variability of the vertical structure for some unknown reason. The observed difference in vertical structure has a consequence on the heat transport: the heat transports diagnosed by LH06 are $0.7 \mathrm{PW}$ for $4 \mathrm{X}$ and $0.4 \mathrm{PW}$ for OVIDE, while the monthly values for the time of the two cruises differ less in the ATL6 model (0.46 PW for 4X and 0.38 PW for OVIDE). 


\section{Thermohaline circulation in density coordinates}

Another view of the thermohaline circulation is provided by the meridional transport integrated in density classes. Following Marsh et al. (2005), we label it here

"THC". We define the upper limit of the cold water by the isopycnal $\sigma_{1}=32.1$, which is representative of the maximum overturning in $\sigma_{1}$ coordinates in the observations (this limit is also suitable for the models). In ATL6, the depth of the $\sigma_{1}=32.1$ isopycnal is realistic in the eastern basin (although not in the Irminger basin). Fig. 6 shows a time-series of the THC strength (southward cold water transport) in the model, along the OVIDE and $4 \mathrm{X}$ sections. Values of the transport are also indicated in Tables 1 and 2. The MOC is smaller than the THC because it includes waters circulating at the same depth but with different densities. This is the reason why a seasonal cycle is present in the THC (Fig. 6) but not the MOC (Fig. 3) where it is cancelled by the seasonal cycle of the East Greenland Current (see next section). Contrary to the MOC, which is consistently larger along the $4 \mathrm{X}$ path (Table 1), the THC is more similar along the OVIDE and $4 \mathrm{X}$ paths, showing that little water mass transformation takes place between the two sections in the ATL6 model. The difference between the two paths is only $0.4 \mathrm{~Sv}$ in the mean.

The THC values for ATL6 (Fig. 6) agree remarkably well with the observations. Data inversion gives $18.9 \pm 0.8 \mathrm{~Sv}$ for $4 \mathrm{X}$ and $16.4 \pm 0.8 \mathrm{~Sv}$ for OVIDE, a decrease of 2.5 Sv (LH06). The decrease in the model is even larger (4 Sv). The model time-series suggests that this could be due to a modest interannual decrease superimposed with higher frequency variability. Examination of the ATL6-clim experiment with repeated seasonal cycle forcing shows that the time-averaged sea- 
sonal cycle has a peak-to-peak amplitude of $4 \mathrm{~Sv}$ and the standard deviation of the remaining signal (due to internal eddy variability alone) is $1.2 \mathrm{~Sv}$. As was the case for the MOC (Fig. 3), the variability of the THC is enhanced in ATL6-02 relative to ATL6-clim, due to high frequency and interannual atmospheric forcing: the standard deviation of the THC for ATL6-02 (Fig. 6) is $4 \mathrm{~Sv}$.

The full time series is not available for the FLAME model, and the estimate of the THC is calculated with less precision than in ATL6. Table 2 shows a difference of $2.8 \mathrm{~Sv}$, which is partly due to the difference in section paths (which is $1.3 \mathrm{~Sv}$ in the mean). The OCCAM model of Marsh et al. (2005, their Fig. 3b) shows a decrease of $3 \mathrm{~Sv}$ of the THC along the $4 \mathrm{X}$ section path. As was the case for the MOC, different models agree on the sign of the variability between 1997 and 2002, although amplitudes vary by one or two sverdrups.

Contrary to the $z$-coordinate MOC, the transport of water in an isopycnal layer is a nonlinear quantity, including the effect of velocity-thickness correlations. Gent et al. (1995) argue that these correlations arise when the fluid is baroclinically unstable and that the resulting transport by the so-called "bolus velocities" needs to be parameterized in low resolution models. Treguier et al. (2003) found that the eddy-induced transport represented one third of the total at $30^{\circ} \mathrm{S}$ in the South Atlantic, due to the complex dynamics of Agulhas eddies there. However, the contribution became small at $20^{\circ} \mathrm{S}$. The eddy induced transport across the OVIDE section is shown in Fig. 7 as the difference between two yearly-averaged curves. The thick curve is calculated from the 5-day model outputs displayed in Fig. 6, taking into account the velocity-thickness correlations. The dashed curve is cal- 
culated from the model annual means, neglecting the eddy effect. The differences are less than $1 \mathrm{~Sv}$, a small value compared to the total $(19 \mathrm{~Sv})$. Such a small effect of eddy correlations may seem surprising considering the findings by Hall et al. (2004) that eddies contribute half the 0.7 PW intergyre heat transport in the ATL6 model. In fact, Hall et al. contrasted the behavior of two sections: one crossed the Gulf Stream ("gyre" transport) while the other ("intergyre") was more or less parallel to the intergyre boundary and thus to the NAC. The eddy contribution was important on the intergyre section but very small on the gyre section. It appears that because the OVIDE section is perpendicular to the NAC, it behaves like the gyre section of Hall et al.; indeed we have verified that the eddy contribution to the heat transport is also negligible in our case. This is due to the fact that eddies tend to carry heat and properties away from the mean current axis; thus the eddy transport tends to be parallel to the OVIDE section rather than across it.

Despite their small value compared with the total transport, the influence of velocity-thickness correlations in the evaluation of interannual variability is not negligible. Ignoring them (the dashed line in Fig. 7) one finds a decrease of $3.7 \mathrm{~Sv}$ in the transport of warm water between 1995 and 2002, while it is only $2.5 \mathrm{~Sv}$ when eddies are fully taken into account (thick line in Fig. 7).

\section{Variability of the current systems}

In this section we use the ATL6 model to examine the variability of the different current systems sampled by the OVIDE cruise. Examination of the 4X path does not bring extra information (the $4 \mathrm{X}$ cruise samples different deep flows around 
the Charlie-Gibbs fracture zone, but this is not well represented in the model). We start from the north, in the Irminger Sea. Water masses are not well represented there by ATL6 (excessive convection and salinization make the water denser than observed at intermediate depths, while the denser overflow water near the bottom of the Greenland continental slope is absent). For this reason, we discuss the barotropic transport along the section, shown in Fig. 8 for both the OVIDE 2002 cruise (LH06) and the ATL6-02 experiment. Starting from Greenland, the East Greenland current (EGC) is found on the continental slope, with a transport of $40 \mathrm{~Sv}$ in the mean in ATL6. Both model and data show a similar structure of barotropic transports in the EGC and the Irminger sea, with quite comparable amplitudes.

With its large southward transport, a large part of which is made of water denser than the northward flowing NAC, the EGC contributes to the balance of the thermohaline circulation. Its variability is not well known at $60^{\circ} \mathrm{N}$ which is the reason why current meter measurements are currently under way along the OVIDE section on the continental slope of Greenland. To diagnose the EGC variability in the model, we need to define an index representative of the EGC strength. We have chosen the barotropic transport between the coast of Greenland and $40^{\circ} \mathrm{W}$ along the latitude of the OVIDE section $\left(59.5^{\circ} \mathrm{N}\right)$. Time series (Fig. 9) shows a large variability in 5-days snapshots, with a peak-to-peak amplitude as strong as $30 \mathrm{~Sv}$. The monthly time series show less variability, and suggest a seasonal cycle. The contrast between experiment ATL6-02 (Fig. 9, top panel) and ATL6-clim (Fig. 9, bottom panel) is striking, and demonstrates that the high variability is a response to 
high frequency wind and fluxes. When forced by a repeated seasonal cycle without synoptic variability, the model EGC variability is weak and seasonal. This seasonal cycle is comparable to the one found in the West Greenland current by Eden and Böning (2002), with a maximum transport in winter and minimum in summer, and an amplitude of about $5 \mathrm{~Sv}$. The variability of the EGC at periods close to a month is found to be of a similar amplitude in ATL6 and the POP $1 / 10^{\circ}$ model of Smith et al. (2000) (not shown), although the mean transports of the two models differ (T05). We thus think that the variability modelled by ATL6 is a robust feature of high resolution models. The model transport is in very good agreement with the LADCP measurements of $4 \mathrm{X}$ and OVIDE (Fig. 9). Note that the EGC variability in ATL6 is consistent with the observations of Fischer et al. (2004) in the Labrador Current: based on current meter data they found maximum of transport in winter and a large variability at periods shorter than a month. Models suggest that this kind of variability is characteristic of the boundary currents over the whole western subpolar gyre.

Moving farther east in Fig. 8, we note a recirculation around the tip of Reykjanes ridge (at $30^{\circ} \mathrm{W}$ ) in ATL6 as well as in the observations. This recirculation is present in float data at mid-depth (Bower et al. 2002). East of Reykjanes ridge, a large anticyclonic eddy appears in the OVIDE data (not in the model) followed by a sharp subpolar front. The front is of comparable amplitude, but smoother and shifted to the West in the model. Other model snapshots however display a front as strong as observed. East of this first front, both model and observations exhibit other large amplitude fronts and recirculations that are time-dependent (compare 
the model snapshot with the time-mean in Fig. 8). A single cruise thus does not bring much information about the multi-year mean barotropic transport structure in the western part of the section.

The main feature of the eastern subpolar gyre is the North Atlantic current (NAC) which carries warm water northwards. The THC strength discussed in the previous section is a measure of its integrated transport; as shown in Fig. 6 it displays a seasonal cycle similar to that of the EGC, with stronger northward transport in winter.

One striking feature of the warm water transport $\left(\sigma_{1} \leq 32.1\right)$ during OVIDE 2002 is the recirculation to the south in the Iberian abyssal plain. LH06 find a transport of $6.7 \mathrm{~Sv}$ to the south, including the Ekman contribution. This flow feature was absent during the $4 \mathrm{X}$ cruise. In their discussion, LH06 separate this recirculation from the northward current flowing on the Portuguese slope (3.8 Sv). This coastal current never exists in ATL6, probably due to a deficiency in the representation of the Mediterranean water. The model's open boundary at $8^{\circ} \mathrm{W}$ in the Gulf of Cadiz has been relatively successful to set the right properties and the right depth of the Med water. However, the flow out of the open boundary tends to be too zonal: too much water leaves the continental slope at Cape St Vincent and too little continues northward along the Portuguese coast. Because the contribution of flow on the slope is negligible in the model, we analyse the total circulation in the Iberian basin (from the coast of Portugal to $15.5^{\circ} \mathrm{W}$ along the OVIDE section). In July 2002 this flow is $10.4 \mathrm{~Sv}$ southward, but the time mean over 1995-2002 is only $1.5 \mathrm{~Sv}$ southward. It is highly variable (Fig. 10, black curve) with both north- 
ward and southward values. It is significantly anticorrelated with the anomaly of the NAC transport between the tip of Hatton Bank $\left(26^{\circ} \mathrm{W}\right)$ and the limit of the Iberian basin (grey curve): recirculation tends to occur when the NAC is stronger. A similar calculation made with experiment ATL6-clim (climatological forcing) shows that such a transient recirculation also happens, with comparable amplitudes. Comparison of the two panels in Fig. 10 shows that the variability of the atmospheric forcing (present in ATL6-02) contributes to high frequency variability and probably some interannual variability in the transports. Because the model eddies are not constrained by observations it is difficult to say whether the large recirculation that happens in the model in July 2002 is significant or just a random occurence. Further study of this variability will be necessary since it may be relevant to changes of the salt export to the Nordic seas, as pointed out by Hátún et al.(2005).

\section{Summary}

This paper was motivated by the first cruise of the OVIDE project in 2002, and its comparison with the $4 \mathrm{X}$ cruise carried out in 1997. Taking advantage of the available numerical experiments in the CLIPPER and FLAME project, we have calculated the meridional overturning and various transports along the cruises' paths in a $1 / 6^{\circ}$ model (ATL6) and a $1 / 12^{\circ}$ model (FLAME). Due to the limitations of the models, the absence of variability in the Nordic seas and also the wrong depth of the overflow waters in ATL6, we do not claim that the models can explain completely the observed changes. We think however that the present diagnostic of 
model variability along the sections can help interpret the present and future data (the OVIDE section will be repeated five times).

Both models show a decrease in the $z$-coordinate meridional overturning between the two cruises, smaller in FLAME than in ATL6, and weaker than observed. The models suggest that the different paths of the two cruises could lead to a significant difference in $z$ coordinate overturning (up to $2 \mathrm{~Sv}$ ) but this value is model-dependent (although models consistently show a larger value for $4 \mathrm{X}$ ). The path of the cruise may affect less the thermohaline circulation in density coordinates (THC). Between the two cruises the observed THC decrease is $2.5 \mathrm{~Sv}$; it is $2.8 \mathrm{~Sv}$ in FLAME and $4 \mathrm{~Sv}$ in ATL6. The full time series of the THC for ATL6 show a large variability on monthly time scales and a weak long-term trend. The model variability is a combination of interannual and high frequency atmospheric forcing, as well as internal eddy effects which account for one third of the total standard deviation. A large part of the forced variability is simply due to the wind-driven Ekman transport. LH06 find two major changes in the overturnings diagnosed for the 1997 and 2002 sections: a weakening of the deep overflows and a weakening of the horizontal circulation (East Greenland current and North Atlantic current). The contribution of the overflows is not reproduced in the models we have considered, but the variability of the other current systems is large enough to produce overturning changes of the same order as the one measured between 1997 and 2002 .

One important result of this paper is the weakness of eddy correlations for the transport across the OVIDE section. Velocity-thickness correlations are negligible 
compared with the mean for the THC, and so are the velocity-temperature correlations for the heat transport. We cannot discard the possibility that these eddy fluxes are underestimated in the ATL6 model due to insufficient grid resolution. Indeed, Penduff et al. (2005) find that there is a deficit of eddy kinetic energy at depth. However, the eddy kinetic energy in the surface layers is quite realistic in the North Atlantic current region in ATL6, and its interanual variability is well reproduced (Penduff et al., 2004). We thus hope that our conclusion may apply also to the real ocean, and that eddy correlations may be safely ignored when analysing the heat transport or THC across the OVIDE line. Based on previous work by Hall et al. (2004), we assume that this smallness of the eddy contributions is simply due to the orientation of the section (perpendicular to the axis of the NAC).

We have performed a first model-based analysis of the variability of the East Greenland current. Although never yet observed, the large variability at periods of a month or less displayed in Fig. 9 should not be surprising. It is similar to the observed variability of the Labrador Current (Fischer et al., 2004). The continuity of the boundary current all around the Northern/Western subpolar gyre suggests that the East Greenland, West Greenland and Labrador currents may all have qualitatively similar variability. In the ATL6 model this variability is completely windforced, but this conclusion may have to be revisited with higher resolution models that would allow more instability of the boundary currents. On the other hand, the modelled variability of the warm water carried by the North Atlantic current and the recirculation to the south in the Iberian basin results in great part from inter- 
nal instabilities, with a smaller contribution from fluctuations of the atmospheric forcing.

As mentioned in the presentation of the model, the CLIPPER project was designed in the context of WOCE and was not intended to study climate fluctuations over decadal time scales. The fact that fluxes and properties are held fixed at the open boundaries artificially supresses potential sources of variability. It is thus not surprising to find differences in the long-term behavior of ATL6 compared with the OCCAM global model (Marsh et al. 2005). Time series of the THC in ATL6 and OCCAM are both compatible with the inversions of LH06. In the case of ATL6, we have found that the observed difference between the cruises can be explained by interannual and shorter term variability independently of any long term (decadal) tendency. However, we must keep in mind that ATL6 does not reproduce the observed change in vertical structure of the MOC, nor in heat transport. OCCAM, on the other hand, suggests a significant decadal trend. Our recent experience with global modelling at $1 / 4^{\circ}$ (Barnier et al., this issue) prevents us from concluding that the global model is necessarily more realistic in its representation of variability between 1997 and 2002. The large domain and complexity of global ice-ocean models bring many sources of artificial drifts, over longer time scales than in limited-area models. Progress in the understanding of the variability in the subpolar Atlantic will require analysing and comparing different models and data, and performing more sensitivity experiments. 


\section{Acknowledgements}

This paper is perhaps the last bringing together the main actors of the CLIPPER project (B. Barnier, G. Madec, J.M. Molines, T. Penduff, A.M. Treguier) and our thanks go to Christian Le Provost for initiating this successful modelling effort. Our collaboration will outlive CLIPPER, as we have now moved on to a new modelling project (DRAKKAR, Barnier et al., this issue). Our new project reinforces the collaboration between the French CLIPPER and German FLAME teams, which dates from the DYNAMO project in which Christian Le Provost also played a major part. One important aim of CLIPPER was to foster collaboration among modellers and "wet feet" oceanographers, and we hope that it is fulfilled in the present study. Members of the CLIPPER project team (as well as H. Mercier) are supported by CNRS and the computations have been made at the CNRS IDRIS computing center in Orsay. P. Lherminier is supported by IFREMER and C. Gourcuff by IFREMER and CNES. The FLAME model studies have been supported by the Deutsche Forschungsgemeinschaft through SFB 460; the computations were performed at the DKRZ, Hamburg. 


\section{References}

1. Alvarez, M., H. L. Bryden, F.F. Perez, A.F. Rios, G. Roson (2002) Physical and biogeochemical fluxes and net budgets in the subpolar and temperate North Atlantic. J. Mar. Res., 60, 191-226.

2. Barnier, B., L. Siefridt, and P. Marchesiello (1995) Thermal forcing for a global ocean circulation model using a three-year climatology of ECMWF analyses J. Mar. Syst., 6 , $363-380,1995$

3. Barnier, B., G. Madec, T. Penduff, J. Molines, A.M. Treguier, A. Beckmann, A. Biastoch, C. Böning, J. Dengg, S. Gulev, J. Le Sommer, E. Remy, C. Talandier, S. Theetten, M. Maltrud, and J. McClean (2006) Recent progress in modelling the global ocean circulation at eddy permitting resolution. Submitted to Ocean Dynamics.

4. Bower, A.S., B. Le Cann, T. Rossby, W. Zenk, J. Gould, K. Speer, P.L. Richardson, M.D. Prater, and H-M Zhang (2002) Directly-measured mid-depth circulation in the northeastern North Atlantic Ocean. Nature, 419 (6907) 603-607.

5. Beismann, J.O., C. W. Boning, D. Stammer (2002) Interannual to decadal variability of the meridional overturning circulation in the Atlantic. A comparison of the response to Atmospheric fluctuations in three ocean models. Clivar exchanges, 25.

6. Czeschel, L. (2004) The role of eddies for the deep water formation in the Labrador Sea. $\mathrm{PhD}$ thesis, Christian-Albrechts-Universität, Kiel, 101pp.

7. de Miranda, A. P., B. Barnier, and W. K. Dewar (1999) Mode waters and subduction rates in a high-resolution South Atlantic simulation, J. Mar. Res., 57, 213-244.

8. Eden, C., and T. Jung, (2001) Variability of the simulated meridional heat transport in the North Atlantic for the period 1951-1993. J. Clim., 14, 676-691.

9. Eden, C., and J. Willeband, (2001) Mechanisms of interannual to decadal variability of the North Atlantic circulation. J. Clim., 14, 2266-2280. 
10. Eden, C., and C. Böning, 2002: Sources of eddy kinetic energy in the Labrador Sea. J.

Phys. Oceanogr., 32, 3346-3363.

11. Fischer, J., F. A. Schott, and M. Dengler (2004) Boundary circulation at the exit of the Labrador Sea. J. Phys. Oceanogr., 34, 1548-1570.

12. Gent, P.R., J. Willebrand, T.J. McDougall and J.C. McWilliams (1995) Parameterizing eddy-induced tracer transports in ocean circulation models. J. Phys. Oceanogr., 25, 463474.

13. Hall, N. M. J., B. Barnier, T. Penduff and J.M. Molines (2004) Interannual variation of Gulf Stream Heat transport in a numerical model forced by reanalysis data. Climate dynamics. 23, 3-4, 341-351.

14. Hátún, H., Sando, A. B., H. Hansen, H. Valdimarsson, 2005: Influence of the Atlantic Subpolar gyre on teh thermohaline circulation. Science, 309, 1841-1844.

15. Hirschi J., J. Baehr, J. Marotzke, J. Stark, S. Cunningham and J.O. Beismann (2003) A monitoring desing for the Atlantic meridional overturning circulation. Geophys. Res. lets., 30 (7), doi 10.1029/2002GL016776.

16. Levitus, S., Boyer, T.P., Conkright M.E., O’Brian T., Antonov J., Stephens C., Stathopolos L., Johnson D., Gelfeld R. (1998) World Ocean Database 1998. NOAA Atlas NESDID 18.

17. Lherminier P., H. Mercier, C. Gourcuff, M. Alvarez, C. Kermabon (2006) Compared analysis of mass and heat transport between Greenland and Portugal in Summers 1997 and 2002, submitted to J. Geophys. Res

18. R. Lumpkin, K. Speer and K. P. Koltermann (2005) Transport across $48 \mathrm{~N}$ in the North Atlantic Ocean. J. Marine Res. (in press)

19. Madec, G., P. Delecluse, M. Imbard, and C. Levy (1998) OPA 8.1 general circulation model reference manual, Notes de l'IPSL, Univ. Pierre et Marie Curie, Paris, 91 pp. 
20. Marsh, R., B.A. de Cuevas, A. C. Coward, H. L. Bryden and M. Alvarez, (2005) Thermohaline circulation at three key sections in the North Atlantic over 1985-2002. Geophys. Res. Lets, 32: L10604, doi:10.1029/2004GL022281.

21. Pacanowski, R. C. (1995) MOM2 documentation, User's guide, and reference manual. NOAA/Geophysical Fluid Dynamics laboratory.

22. Penduff, T., B. Barnier, W.K. Dewar, J.J. O'Brien (2004) Dynamical response of the oceanic eddy field to the North Atlantic oscillation: a model-data comparison. J. Phys. Oceanogr., 34, 2615-2629.

23. Penduff, T., B. Barnier, J.M. Molines, G. Madec (2005) On the use of current meter data to assess the realism of ocean model simulations. Ocean modelling, in press.

24. Reynaud, T., P. Legrand, H. Mercier and B. Barnier (1998) A new analysis of hydrographic data in the Atlantic and its application to an inverse modeling study, Int. WOCE Newslett., no.32, 29-31.

25. Treguier, A.M, B. Barnier, A. P. de Miranda, J.M. Molines, N. Grima, M. Imbard, G. Madec, C Messager, T Reynaud, S Michel (2001) An eddy permitting model of the Atlantic Circulation: evaluating open boundary conditions. J. Geophys. Res., 106, 2211522129.

26. Treguier, A.M., O. Boebel, B. Barnier, and G. Madec (2003) Agulhas eddy fluxes in a 1/6 Atlantic model. Deep Sea Res., II, 50, 251-280.

27. Treguier, A.M., S. Theetten, E Chassignet, T. Penduff, R Smith L Talley C. Böning, J.O. Beismann, (2005) The North Atlantic subpolar gyre in four high resolution models. J. Phys. Oceanogr., 35: 757-774.

28. Willebrand, J., B. Barnier, C. Böning, C. Dieterich, P. Hermann, P. D. Killworth, C. Le Provost, Y. Jia, J.M. Molines, and A. L. New (2001) Circulation characteristics in three eddy-permitting models of the North Atlantic, Prog. Oceanogr., 48, 123-161. 


\begin{tabular}{|c|c|c|c|c|c|c|}
\hline & \multicolumn{3}{|c|}{ 4x path } & \multicolumn{3}{c|}{ Ovide path } \\
Time period & $z$-MOC & б-THC & Ekman & $z$-MOC & $\sigma$-THC & Ekman \\
\hline mean 1995-2002 & -13.6 & -19.5 & -1.3 & -12.1 & -19.1 & -1.1 \\
Year 1997 & -14.1 & -21.1 & -0.9 & -12.7 & -20.1 & -0.7 \\
Year 2002 & -12.7 & -18.6 & -1.6 & -11.6 & -18.4 & -0.8 \\
August 1997 & -13.4 & -17.8 & -1.8 & -12.1 & -16.4 & -1.3 \\
July 2002 & -13.5 & -14.9 & -0.8 & -10.6 & -13.8 & -1.2 \\
\hline
\end{tabular}

Table $1 z$-coordinates meridional overturning (MOC), $\sigma$-coordinates thermohaline circulation (THC) and Ekman transports (Sv) in the ATL6-02 model experiment along the paths of the $4 \mathrm{X}$ and OVIDE sections at various times (see text for definition). Ekman transports are calculated directly from the model wind stress (ECMWF). Negative transports represent southward flows (southward flow of deep water in the case of the MOC and THC). 
A.M. Treguier et al.

\begin{tabular}{|c|c|c|c|c|c|c|}
\hline & \multicolumn{3}{|c|}{ 4x path } & \multicolumn{3}{c|}{ Ovide path } \\
Time period & $z$-MOC & $\sigma$-THC & Ekman & $z$-MOC & $\sigma$-THC & Ekman \\
\hline mean 1995-2002 & -9.3 & -15.6 & 1.6 & -8.7 & -14.3 & -0.8 \\
August 1997 & -8.9 & -14.7 & 0.7 & -8.7 & -12.9 & -0.3 \\
July 2002 & -10.6 & -13.7 & 0.6 & -7.9 & -11.9 & -0.5 \\
\hline
\end{tabular}

Table $2 z$-coordinates meridional overturning (MOC), $\sigma$-coordinates thermohaline circulation (THC) and Ekman transports (Sv) in the FLAME $1 / 12^{\circ}$ model along the paths of the 4X and OVIDE sections at various times (see text for definitions). Ekman transports are calculated directly from the model wind stress. Negative transports represent southward flows (southward flow of deep water in the case of the MOC and THC). Note that the THC values for FLAME are calculated from monthly means by binning transports in full model cells, which is less accurate than the calculation performed for ATL6 (from 5 days snapshot with linear interpolation of the isopycnal position within a cell). 


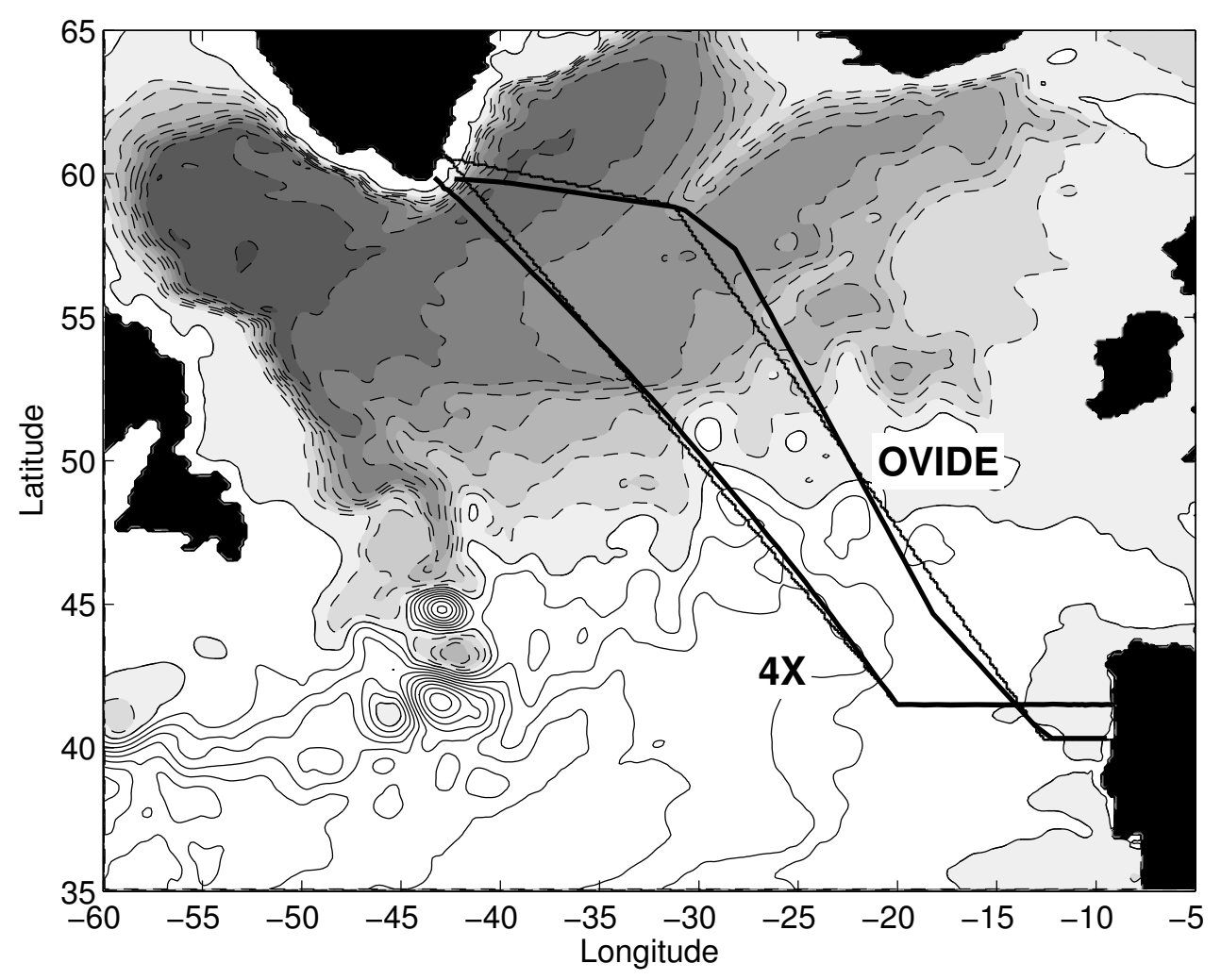

Fig. 1 Time-mean barotropic streamfunction in the ATL6-02 experiment. Contour interval is $5 \mathrm{~Sv}$, negative contours are dashed and filled with grey. The path of sections $4 \mathrm{X}$ and OVIDE are shown: thick lines represent the actual observations, and the thin lines represent the approximate paths used for calculation of the model mass fluxes. 


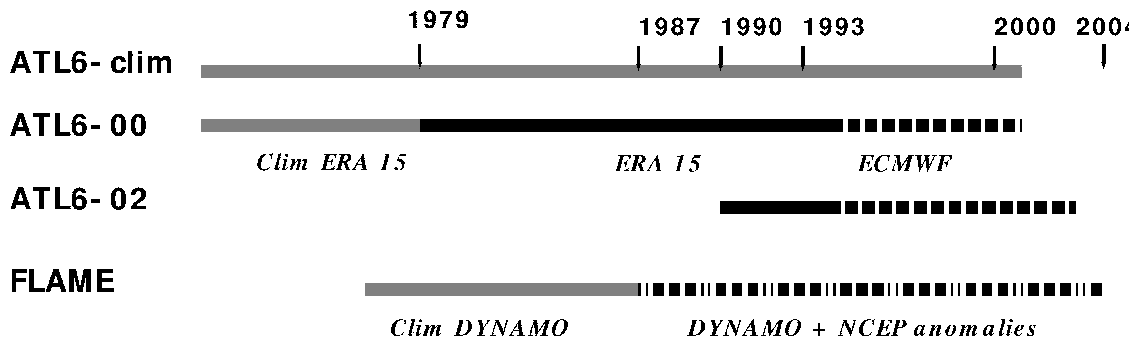

Fig. 2 Summary of the model experiments used in this paper. Grey lines represent climatological forcing and black lines interannual forcing (see text for details). 

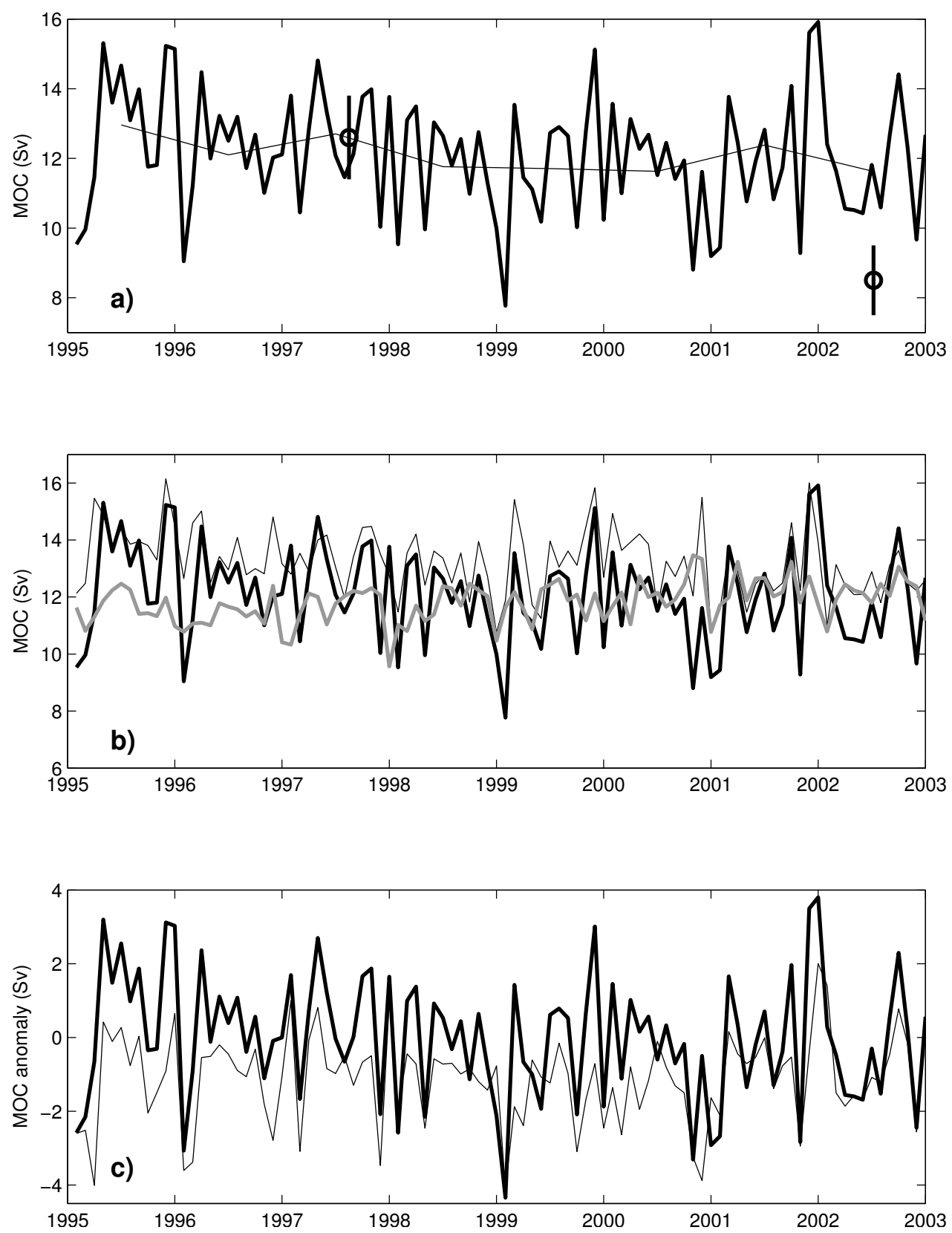

Fig. 3 a: Monthly (thick line) and annual mean (thin line) time series of the total MOC for ATL6-02 calculated along the OVIDE path; symbols represent observed values for the 1997 and 2002 cruises with error bars (LH06). b: Monthly time series of the total MOC for ATL6-02 (standard deviation is 1.7), for ATL6-02 with Ekman contribution removed (thin line, standard deviation is 1.2) and monthly time series of the total MOC in experiment ATL6-clim with climatological forcing (grey line, standard deviation is 0.7). c: Monthly time series of the MOC anomaly in ATL6-02 (thick line) and Ekman transport contribution (thin lines, counted positive southwards). Note that we have plotted the full Ekman transport rather than its anomaly (the mean is $-1.1 \mathrm{~Sv}$ ) because this enhances readability. 

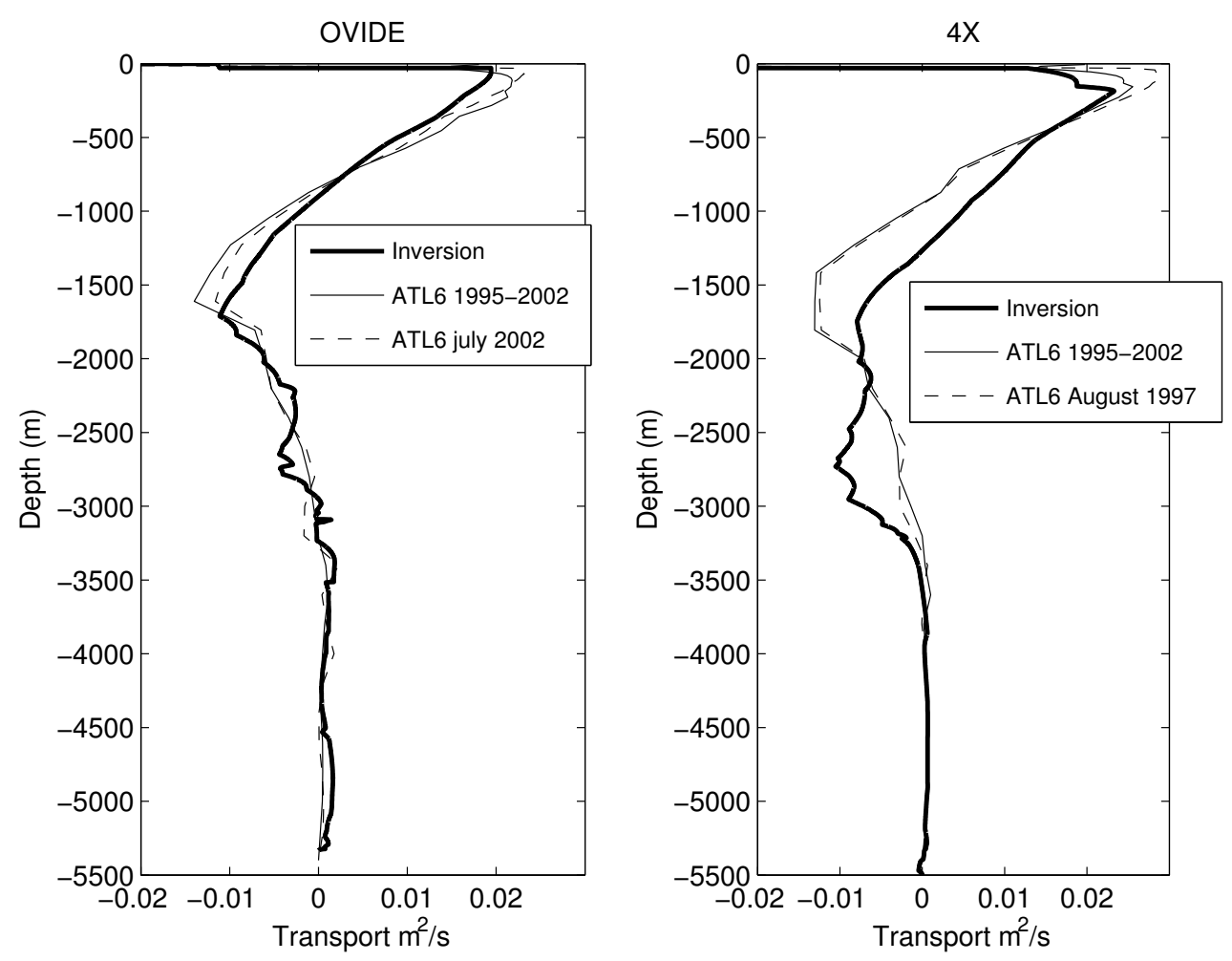

Fig. 4 Vertical structure of the transport along the OVIDE (a) and 4X (b) paths, for the ATL6-02 model and observations (inverse estimates of LH06). Model results are shown for the time mean (1995-2002) and a monthly mean at the time of the cruise. 

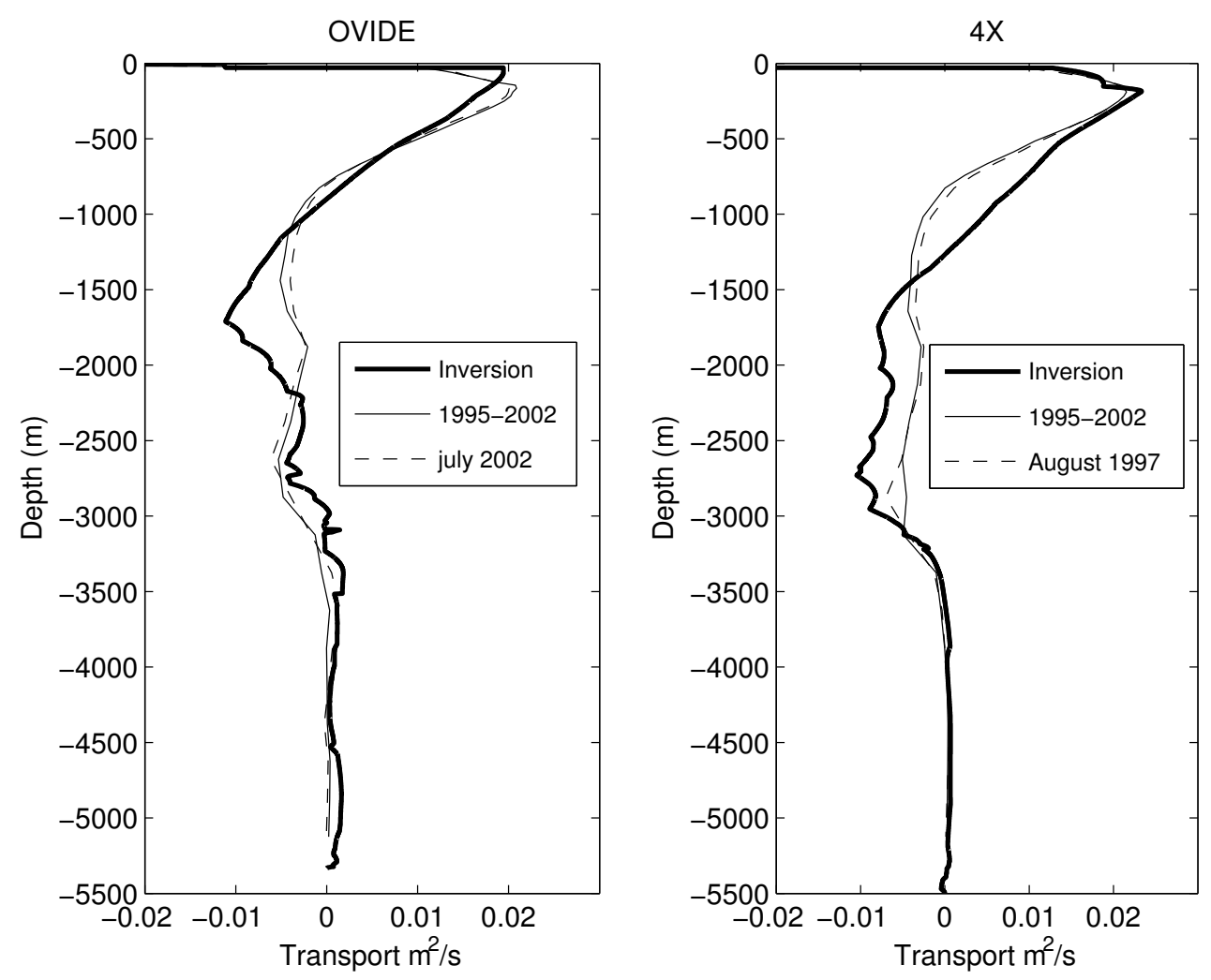

Fig. 5 Vertical structure of the transport along the OVIDE (a) and $4 X$ (b) paths, for the

FLAME model and observations (inverse estimates of LH06). Model results are shown for the time mean (1995-2002) and a monthly mean at the time of the cruise. 


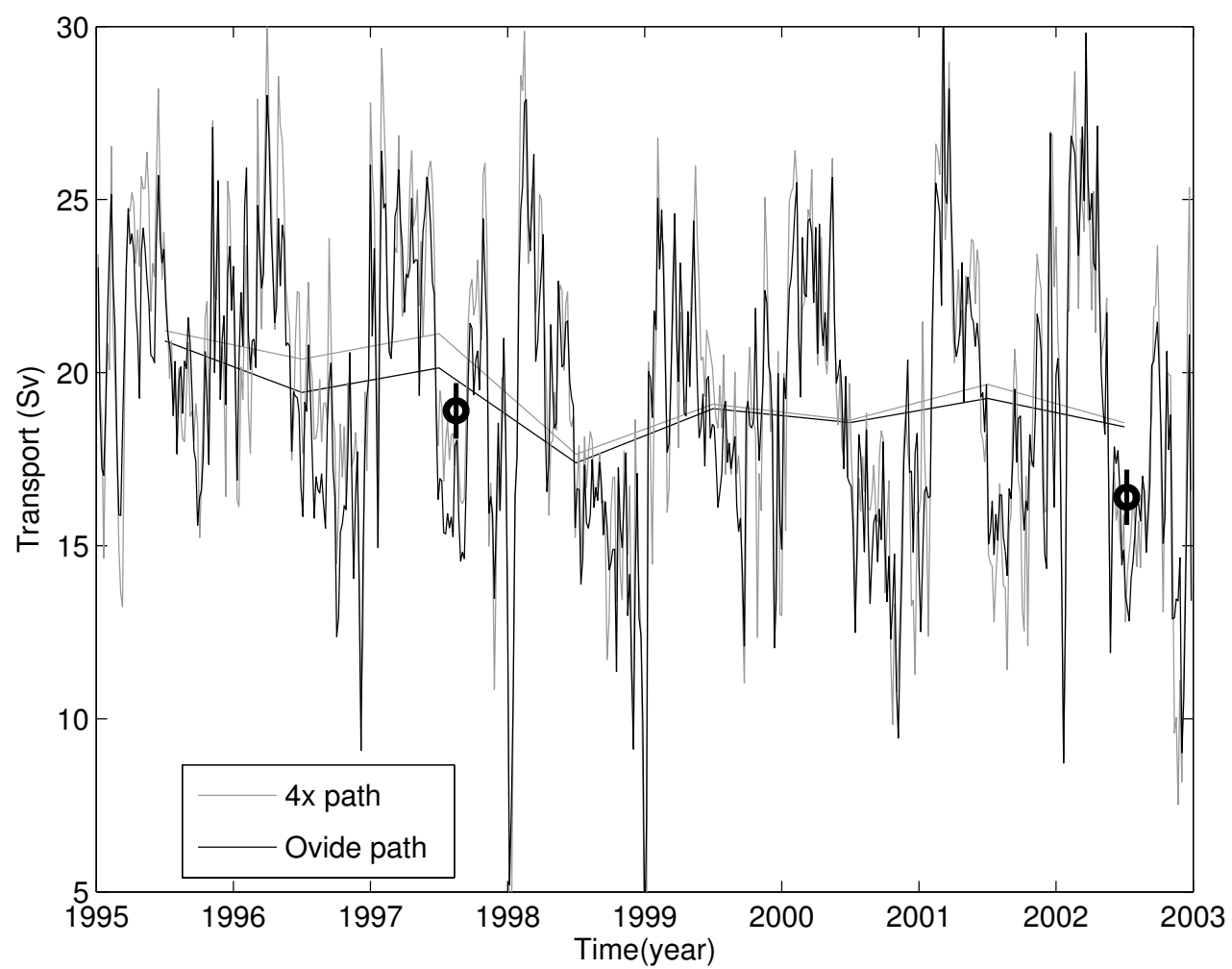

Fig. 6 THC measured by the transport of water denser than $\sigma_{1}=32.1$ (counted positive southwards), calculated from 5 days outputs of ATL6-02. Black lines correspond to the OVIDE section and grey lines to the $4 \mathrm{X}$ section. A smoothed curve of yearly averages is also indicated. Symbols represent observed values for the 1997 and 2002 cruises (LH06). 


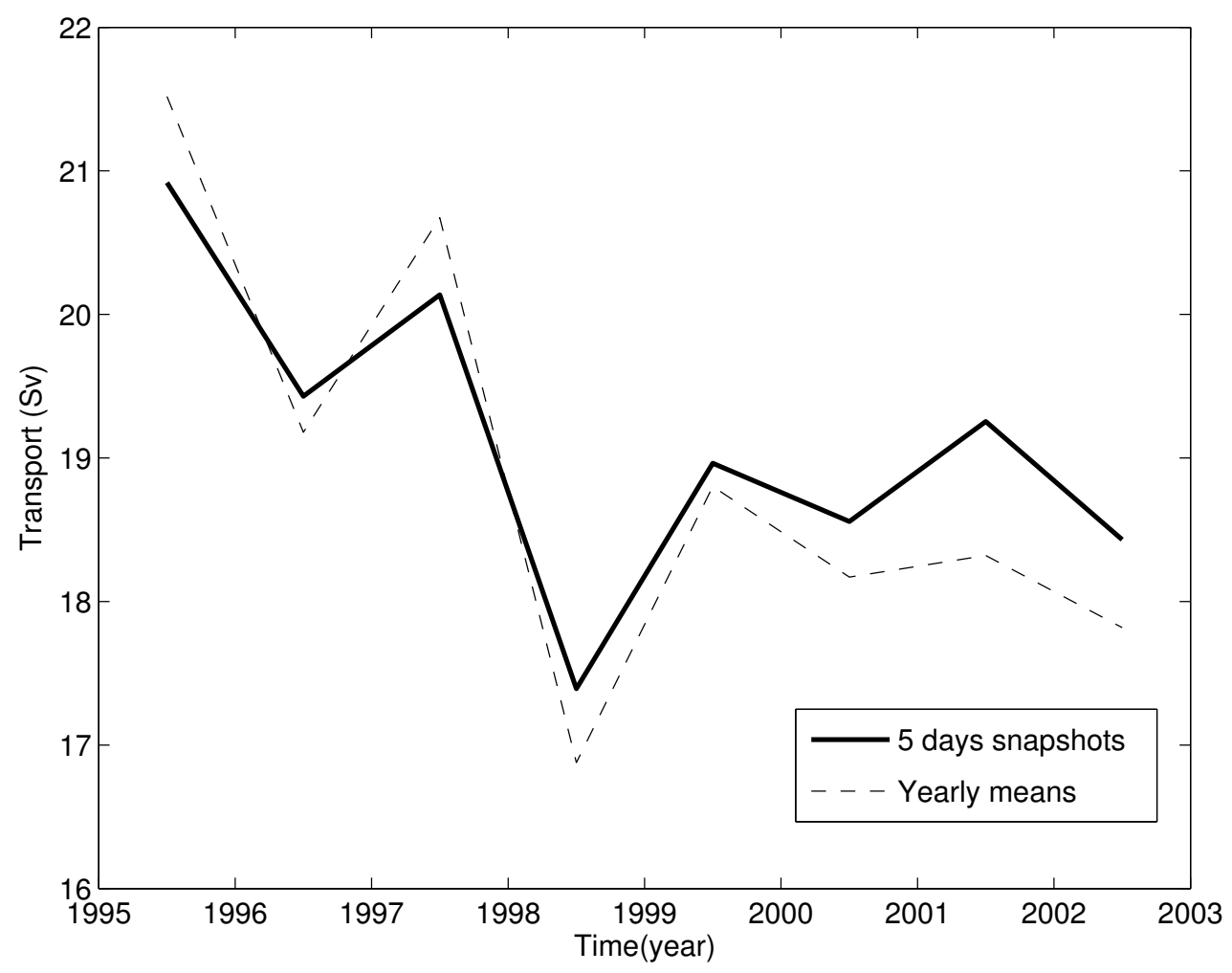

Fig. 7 Annual average of the THC along the OVIDE section. The thick black curve is estimated from 5 days outputs of ATL6-02 (same curve as in Fig.6). The dashed line is a calculation using the model annual mean fields. The difference between the two annual mean curves is the transport by eddy-induced velocities. 


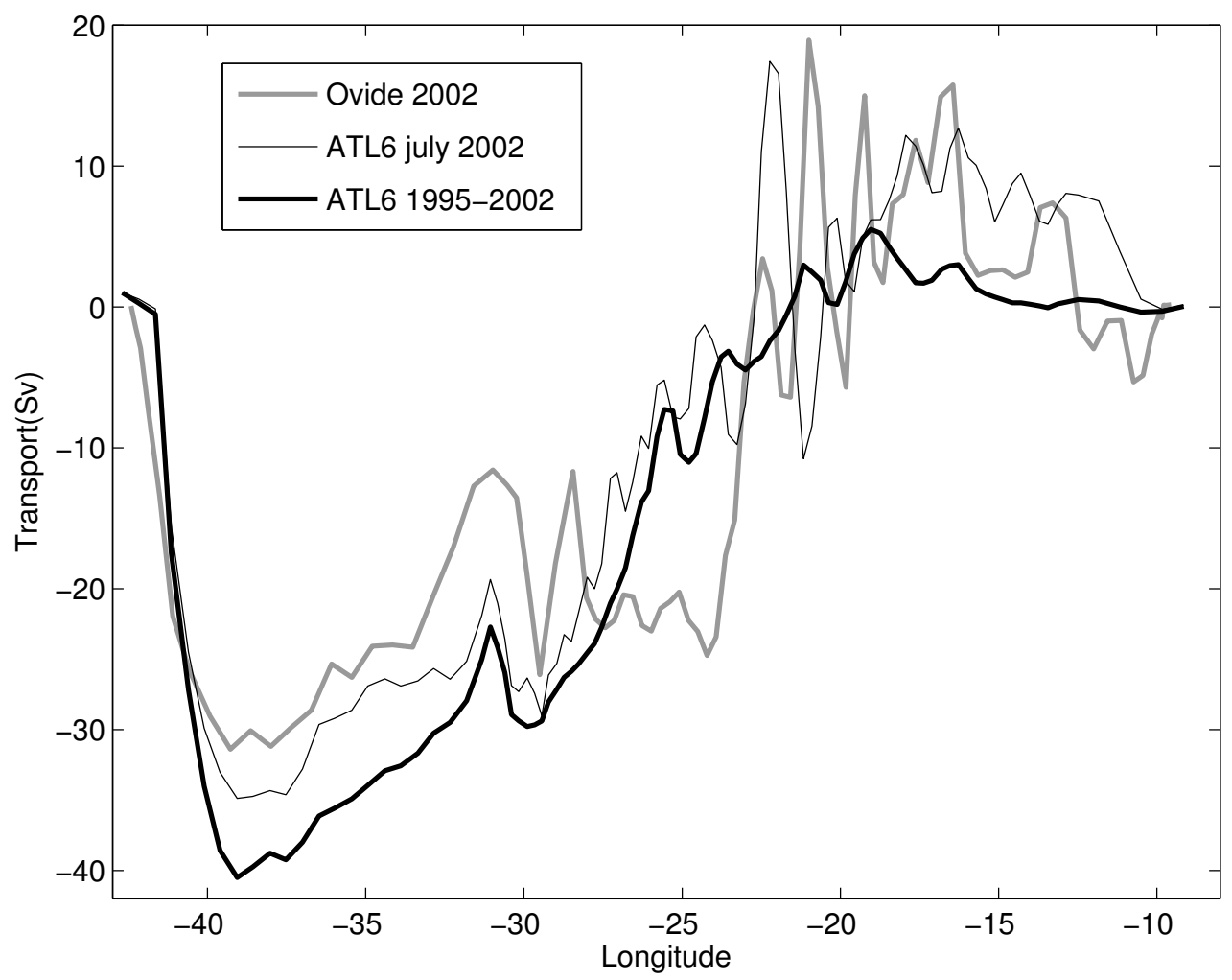

Fig. 8 Barotropic transport through the OVIDE section (positive northwards). Data resulting from the inversion of LH06 are shown in grey. The thin black curve is a model snapshot during the month of the cruise (July 2002) and the thick black line is the average of years 1995-2002. Model results are integrated spatially over 4 grid points for better consistency with observations. 

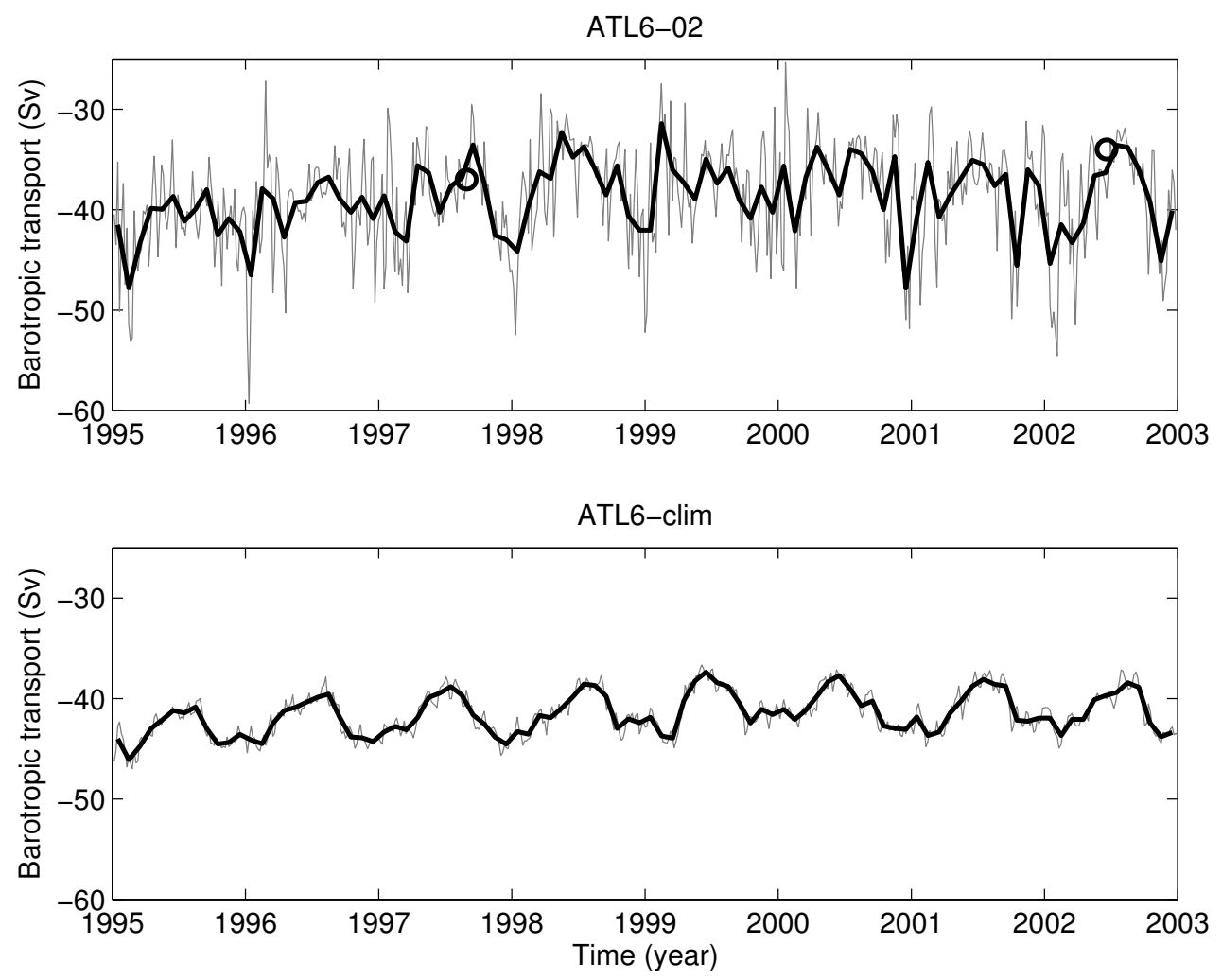

Fig. 9 Barotropic transport streamfunction at $59.5^{\circ} \mathrm{N}, 40^{\circ} \mathrm{W}$ representative of the EGC transport. The grey curve is from 5-days outputs and the black curve from monthly outputs. Values measured by the LADCP for cruises $4 \mathrm{X}$ and OVIDE are indicated by the black circles (37 Sv and $34 \mathrm{~Sv}$, respectively, LH06). Top panel: ATL6-02 experiment; bottom panel: ATL6-clim experiment. 

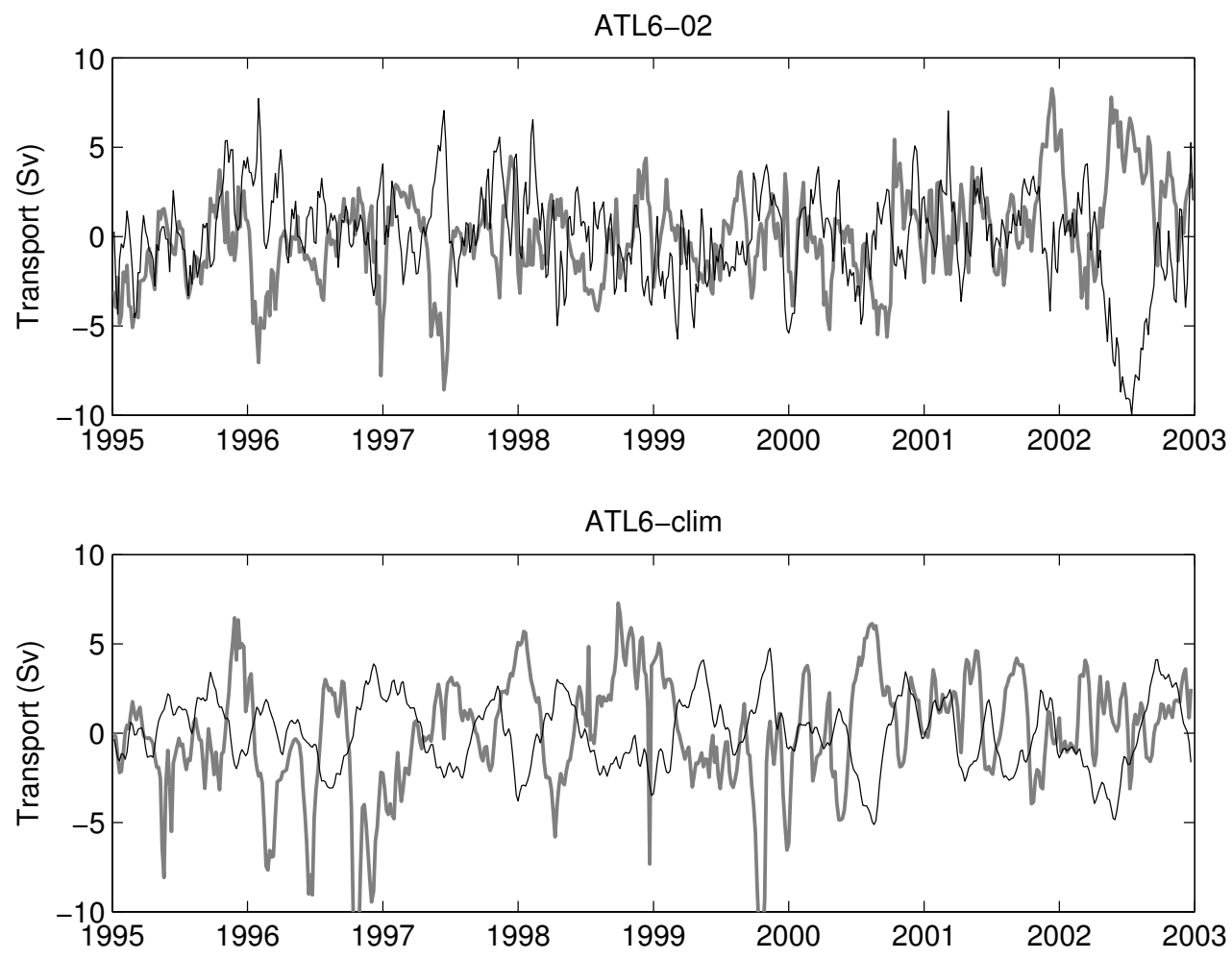

Fig. 10 Anomalies of transport for the water lighter than $\sigma_{1}=32.1$ along the OVIDE section calculated from 5 days outputs of ATL6-02 (top panel) and ATL6-clim with climatological forcing (bottom panel). The black curve is the transport anomaly integrated in the Iberian basin (east of $15.5^{\circ} \mathrm{W}$ ) and the grey curve is the NAC transport defined between $15.5^{\circ} \mathrm{W}$ and the tip of Hatton bank $\left(26^{\circ} \mathrm{W}\right)$. Mean values are $20 \mathrm{~Sv}$ (NAC) and $-1.5 \mathrm{~Sv}$ (Iberian basin) for ATL6-02, and $21 \mathrm{~Sv}$ and -2 Sv for ATL6-clim. 